\title{
The Traditional Conception of Diathesis (Voice) and a Modern View to It
}

\author{
Ph. D Albana Deda \\ Department of Albanian Language, \\ Faculty of History and Philology, \\ University of Tirana, Albania
}

Ph. D Leonora Lumezi

English Department, Faculty of Foreign Languages,

University of Tirana, Albania

Abstract

Since the antiquity, diathesis has been analyzed in linguistic theories as a morphological category of the verb. Consulting the earliest papers, there could be noticed that Greek tradition makes mention of active, passive and middle verbs, whereas in Latin papers we find active and passive verb forms. (There must be said that during this linguistic period the term diathesis could hardly be found. The above mentioned terms referred to the classification of verbs). During the Medieval Age linguists defined the same concept of diathesis. Most of the traditional grammars of many contemporary languages hold the same view, without any significant differences. In traditional Albanian papers diathesis or voice is defined as a morphological category that expresses relations between the verb (the traditional predicate) and the subject. There has been made a division between active and non-active voice. Non-active voice verbs are further divided into: passive, reflexive and middle voice. Empirical studies show that it is difficult to make a distinct and final classification of verbs in terms of the different patterns in which it can be found. This inference is made taking into consideration abundant examples from the Albanian corpus, showing that a verb can be used intransitively in some patterns and transitively in others. The voice division of verbs provided by the Albanian grammars reveals a gap in the examination of the formal and especially the semantic aspect. There are many semantic and formal arguments that lead us to the conclusion that the traditional definition of diathesis is problematic. In our view, this process should be treated as a wider phenomenon that includes more than the morphological aspect. The Valency Theory could be an alternative approach that provides a better solution to this problem.

Keywords: Traditional Conception, Diathesis, Voice, Modern View

The studies on diathesis in the Albanian language are of an early origin. Obviously, the main sources to consult are the first grammars. The conception of this process by each grammar book has its own peculiarities. However, what could undoubtedly be asserted is that they do not provide a unified perception of diathesis, even though, apparently, the terms used are almost the same. On the other hand, in certain cases this concept, which was traditionally viewed as a morphological category, is characterized mainly formally, thus leaving aside the other aspects of linguistic study that are involved in this process. In this paper we focus only on the concept defined and examined by Grammar I', because its definition is widely and solely referred to by all pre-university textbooks (some of which literally cite it), and also because, unfortunately, even in the research conducted at a university level, there are no new treatments of this topic or discussions on it.

Grammar I provides the following definition of diathesis/voice: "Diathesis is a grammatical category, which expresses the relationship between the action expressed by the verb and the subject (overt or implied) of the sentence. "The relations to

\footnotetext{
1 In the Grammar of 2002 there are only two pages clarifying this concept.
} 
the subject of the sentence are morphologically expressed by two forms that oppose each-other, which will be called the active form and the passive form of the verb'."

Further on it emphasizes the fact that this book refers to the narrow conception according to which the intransitive verbs have no voice forms (active or passive). There are mentioned the active, passive, middle and reflexive voice forms.

The definition appears quite baffling, because it refers to a morphological grammatical category, which has traditionally been described mainly formally, within the boundaries of words and their paradigms and, on the other hand, it discusses the relations between sentence elements (subject- verb) which traditionally belong to a syntactic level of analysis. Therefore, it is not clear what relations (morphological or syntactic) this "morphological category" focuses on. The analysis leaves apart the semantic aspect, which is very important concerning the topic under discussion. It creates the impression that these relations could be explained by a formal analysis, i.e. morphologically expressed by the formal contrast active/ passive voice, but a simple pragmatic analysis of the definition provided shows that the above implication is only part of a broader process and not a limited morphological one.

The exclusion of intransitive verbs, despite the fact that one of its paragraphs affirms that they might have an active form (according to Grammar I, the intransitive verbs usually have active and passive forms, except for some cases, as mentioned in the book, when they are used as one-person or impersonal verbs, s'rrihet, s'më rrihet ${ }^{2}$ ), suggests that such examples exist.

It is surprising that the intransitive verbs are excluded from the analysis, taking into account the fact that, as justified by the above mentioned historical description, most of the authors accept that the intransitive verbs can have active or passive voice forms, an opinion shared also by Prof. Demiraj, whose analysis is, in our opinion, represented in Grammar I, according to which a verb can be used with different meanings in different contexts, even though he does not include the intransitive verbs in this process.

On the other hand, some linguists dealing with rection ${ }^{3}$, have mentioned the existence of verbs with zero, one, two, and three rections, almost structurally (not semantically). Thus, we could certainly conclude that it is impossible to make a precise division of verb uses without comparing the instances of use structurally and semantically with others. Also, if such an analysis were made, we could notice that an intransitive verb (with a zero rection), can appear in other one or tworection structures, as claimed by Riza e Dhrimo. But, such an analysis goes beyond the boundaries of morphology, because it involves the syntactic and semantic level as well, without which it would be incomplete.

Viewed from this perspective, what follows is a description of the verb corpus and structures related to intransitive verbs, represented in Grammar I4. The intransitive verbs mentioned in this book are verbs that denote state and movement: fle, dremit, dal, eci , shkoj, hyj etc. It is distinguishable that each of these verbs can be used transitively and intransitively, as stated in the book, where the author confirms that there are no clear-cut boundaries between the one group and the other, despite it being clarified that it is the context that determines whether a verb is transitive or intransitive. As can be observed, the semantic criterion (in our view, semantic and structural) performs an important function in making this distinction, but the present study does not provide a thorough analysis of it. It is known that the semantics of different verbs is not related only to transitivity or intransitivity. There are impersonal verbs that have no agents, as well as there are others that control patient subject5: (Ai fle (He sleeps)), goal (Goli erdhi. (The goal came)), instrument (Thika është mbi tavolinë.(The knife is

\footnotetext{
1 Grammar I, Academy of Sciences of Albania, Tirana, 2002, p. 270.

2 Grammar I, Academy of Sciences of Albania, Tirana, 2002, p. 264-265.

3 S. Riza Sistemi foljor i letrarishtes bashkohore, Tiranë ,1994/ A. Dhrimo, SF, 1965, nr.2.

${ }^{4}$ Grammar I, Academy of Sciences of Albania, Tirana, 2002, p. 264-265.

${ }^{5}$ K. Tarvainen, Semantic cases in the Framework of Dependency Theory, 1985.
} 
on the table)) etc. This fact is acknowledged by the author of the book, since he focuses on the verb pësoj which, despite taking an object, "semantically, it is not used as such".

Given the above analysis, we could infer that the difficulty in determining the exact voice form of the verb appears right from the outset, because there is no sustainable semantic and syntactic criterion (the verb pësoj) to rely on. In addition, we think that the exclusion of the intransitive (traditional) verbs makes the analysis less convincing. Following are some groupings provided by the book for each verb voice form (diathesis). The verb is active when it has an active form and denotes an action that is done by the subject, as stated in the Grammar. As can be noticed, the formal criterion is mentioned first (active form), and the semantic one (to some extent), second. It is known that intransitive verbs have an active form, but there are transitive verbs that control a non-agent subject.

Atij i vdiq i ati në një aksident.(His father died in an accident)

Boja hidromat lyen muret( this paint paints the walls), kurse kjo tjetra përdoret për të pikturuar.

In our opinion, the subject of the first sentence above is not the agent of the action, but the patient (traditional term) or the experiencer (terminology of semantic cases). Also, in the second sentence the subject is an instrument, and not an agent. Thus, we might infer that both criteria, the semantic and the morphological one, pose problems, whereas the structural criterion which realizes the first two, is not analyzed thoroughly. Grammar I also provides that a verb is in the passive, reflexive and middle voice form when it has a non-active form and names an action which is suffered by the subject if the verb is in the passive voice form, it is performed and suffered by the subject if the verb is in the reflexive voice form, and is performed by the subject itself if the verb is in the middle voice form.

Considering this treatment, we notice that there is no formal contrast between these three voice forms, since the three of them are morphologically expressed by a non-active form.

If we focus on the semantic aspect, we could notice that the definitions provided for the middle voice and active voice verbs are the same (they express an action performed by the subject). So, between them there is no semantic distinction. What distinguishes one form from the other is only the morphological marker. This runs contrary to the definition of diathesis/ voice provided in the book. Also, the middle voice verbs are not semantically contrasted to intransitive verbs, since in the verb groups mentioned in Grammar I, these are verbs that denote state, movement, etc, semantic shades that also pertain to intransitive verbs (they also denote state and movement). In addition, the book ignores the formal contrast between them, since it states that intransitive verbs can be used in non-active forms (their impersonal and one-person uses s'rrihet, s'më rrihet).

The semantic contrast between middle voice verbs and reflexive voice verbs is also difficult to notice given that the representatives of the group of reflexive verbs (lahem krihem vishem, etc. (wash, comb, dress, etc.)), in most of the contexts, do not emphasize the fact that they "suffer" the action performed by the subject. We know that a human being of a normal psycho-motor development, at a certain age does all these processes by him/herself, so this is included in the semantic nucleus of the verb itself (semantic valency to be more precise). Moreover, the discourse structures have marked this fact by the use of the reflexive pronoun vetë, which appears in cases other than the ones mentioned above. So, when talking about a child or a handicapped person we could say that "Ai u la vetë"(He washed himself), but this cannot be used about every normal human being. There is no formal contrast here, because both forms are non-active. An ordinary speaker could not distinguish between the agent and patient in the following sentence:

Ai u la, u vesh dhe u largua si gjithmonë. 
(He washed, dressed and left as always)

According to Grammar I, the first two verbs are reflexive, whereas the third one is a middle verb.

Some grammarians have included them in one big group, that of reflexive verbs.

In the following examples we will consider that the semantic contrast realized in specific syntactic structures ignores the differences between the other diathesis.

Ai u vra.

Ai u vra vetë.

Ai vrau veten.

The verb in the first sentence is traditionally analyzed as passive, although the sentence lacks a reason adjunct. On the other hand, the second sentence which is similar to the first as to its morphological structure, is followed by the reflexive pronoun vetë which changes the meaning of the verb, thus changing its voice from passive to reflexive. The most problematic is the third sentence which has got a verb in the active form and whose subject not only performs the action but is also acted upon. This is this is expressed by the reflexive "veten" which in the sentence is a complement.

In our opinion, the active voice verbs display a huge gap in precisely determining the semantic criterion. Thus, according to the traditional approach, in the sentence "Blerina ndez dritën", we have to do with an active voice verb because it is a transitive verb, takes a direct object and the subject is the agent.

The two complements of this structure represent the following components: the subject, the agent [+active], [+intentional] and the object, the patient [- active], [- intentional].

However, the same head verb in the same form (active), can select other arguments that are also realized by an [NP] the meanings of which could have different semantic cases. One such structure is the following:

Blerina ndez(i) dritën e shpresës (te ne).

The complements in this sentence are formally similar (the accusative noun is expanded by another obligatory constituent, the traditional modifier, which modifies the head noun and gives an utterly different meaning to the sentence under discussion).

Blerina is again analyzed as the agent, dritën e shpresës in this case is [-active], [-intentional], [+virtual]1.

In the first example we talk about an [+objective] perception, because it expresses an objective physical process, perceived by the senses visually, objectively.

The second example expresses a figurative, emotional perception through a metaphor.

Some idiomatic verb phrases are also problematic. According to Grammar I these units have got a finite head verb form. When they are morphologically and semantically analyzed they are taken as an inseparable single unit as they really are. Frequently, the semantics of these units does not correspond to their morphological form. Thus, such units as kam frikë, lë nam etc, which at first glance would be described as active, because the verbs of these unit are active voice verbs, are equivalent to their non-active forms frikësohem, turpërohem, which are included in the non-active verb group.

\footnotetext{
${ }^{1}$ According to "Fjalori i gjuhës hqipe" (1980) this verb can control arguments that are completely different from its first meaning (ndez shpirtin, ia ndezi surratit, nuk i ndezi me të etj.).
} 
Given the above analysis, we could conclude that with respect to active voice verbs, the semantic criterion is almost ignored. On the other hand, the concept of voice/diathesis cannot be restricted to a subject-verb relationship, which is only part of what the wide discourse corpus offers.

Our analysis (which considers a few of the many examples found in the discourse), shows that voice is a broad process and not a simple grammatical category, as defined by Grammar I. An accurate perception of it is possible only if we examine the data coming from the three linguistic levels, i.e. semantic, syntactic and morphological one. It is impossible to define this process based on the subject- verb relations only, without taking into consideration the distribution of the verb head. Furthermore, we cannot draw on the traditional semantic characterizations that do not provide a clear explanation of the semantic aspect. There should be analyzed all potential patterns of verb phrases, the verb heads and their distribution. The arguments that the verb head involves should be described using the terminology of semantic cases that give a clear view of the message conveyed by the structure.

The above mentioned reasons urged us to find other solutions concerning the voice. Our conclusions and perception with regard to this process come close to the analysis found in descriptive theory known as the Valency Theory.

This theory has for a long time been related to Tesnièr and his Dependency Grammar ${ }^{1}$. At the same time it was introduced first in Germany and later in other countries.

In this context, the German scholars refer to the studies of Bühler, 1934, Groot, 1949, etc, which are considered a significant contribution in terms of descriptive studies on this phenomenon ${ }^{2}$, in Germany. These scientific studies resulted in the publication of the first valency dictionary of German verbs in 1968.

Outside Germany there was a growing interest about this theory and almost parallel to the developments there, there were introduced studies of such scholars as Hays (1964), Gaifman (1965) and Robinson (1970). Later this tradition would be followed by Anderson (1971, 1977), Hudson (1976, 1984, 1990), Miller (1985), Melcuk (1988), Starosta (1988) etc.

At present, there are many renowned linguists who have made a serious contribution to this field, such as Thomas Herbst, Charles Fillmore, Rudolf Emons, David Allerton, Peter Mathews, Katrin Götz-Votteler, Michael Klotz etc, to name but a few.

Valency theory attributes a central role to the verb seeing the verb as the element that determines how many other elements occur in a sentence.

With reference to valency, there have been two main approaches. One of them views valency as a phenomenon of a formal dependency between heads and the elements controlled by them. This dependency involves a certain number of complements or arguments. Such findings resulted in conclusions that were more related to quantitative valency (the number of arguments controlled by the head). Consequently, the verbs were divided into monovalent, divalent, trivalent, etc.

This division was in fact very sketchy and did not represent all the potential valences of the head analyzed. What confirms this inference is the fact the semantic analyses attempted by representatives of this approach were fewer and less profound as compared to those of the second approach.

The latter is broader because it views valency as a universal semantic asset ${ }^{3}$. The linguists who share this perspective have made a valuable contribution to a reconsideration of the semantic aspect which is, beyond doubt, of great importance in this process and is viewed from several perspectives, such as the study of the semantic categories, the semantic components, the specific description of verbs, semantic roles, etc. It must be emphasized that the major products of this

\footnotetext{
1 Lucien Tesnière, La Grammaire Structurale, Paris, 1959.

${ }^{2}$ A similar concept is presented by Bühleri (1934), Groot (1949). Later, a significant contribution in this field was made by Gerhard Helbig, which was followed by the Valency Dictionary of German (Helbig and Schenkel, 1968, Engel and Schumacher, 1976).

${ }^{3}$ See Allerton/Emons, p.2.
} 
theory are the valency dictionaries of such languages as German, English, French, etc. On the other hand, the principles of this theory are widely applied to the creation of a structural computational corpus of several languages.

The verbs in these studies appear to semantically select arguments which in the surface structure appear to be complements expressed by phrases of specific types. The term argument is related to the semantic analysis and is clarified by the elements of the semantic velency, such as the semantic cases, semantic components, verb description ${ }^{1}$, etc. The term complement represents the syntactic level and is expressed by a specific phrase type. The verbs are given with their formal markers of the active or passive voice in concrete patterns. In this way, a considerable number of valency patterns is described indicating the verb head projections and their different semantic roles.

Below we give the valency patterns of a verb according to the Valency Theory, referring to the Albanian structure:

\section{A. ACCUSE ${ }^{2}$ - VERB}

ACTIVE $1 / 2$

I obl $[E] A /[E] P$

II obl $[E] A /[E]_{1}[\text { for E }]_{2}$

III kon $[E] P$

IV $\quad[E] P /[$ for E]
PASSIVE $\quad 1 / 2$

Active[+inst]/l prek

Active/l prek

Përf
Impersonal/ 0

$\mathrm{D}_{2}$

$D_{6}$ $\mathrm{T} 10$

Përf/Shkak

$D_{6}$

D-The court accused him /Gjykata e akuzoi atë

T-The court accused him (them, me, you (sing $+\mathrm{pl})$, he) of abuse of office, theft, robbery, murder, sexual abuse etc.l Gjykata e akuzoi atë (ata, mua, më,ty, ju,ai) për shpërdorim detyre, vjedhje, grabitje, vrasje, abuzim seksual etj.

M- He (/she; they (fem+masc); we; you (sing+pl), I) were already accused. /Ai(/ajo; ata/ato; ne ; ju; ti; unë) u akuzua tashmë.

D- He was accused of abuse of office, theft, robbery, murder, sexual abuse etc. / Ai u akuzua për shpërdorim detyre, vjedhje, grabitje, vrasje, abuzim seksual etj.

\section{B. BLAME}

\section{ACTIVE $1 / 2$}

II obl $[E] / /[E] P$

I kont $[E]_{A}$

II $[E] P /[$ from E]

III $[E] p /[\text { from E] }]_{1 /[\mathrm{me} / \mathrm{pa} \mathrm{E}] 2}$ I prek/ Vep/Mën
PASSIVE $1 / 2$

Vep[+frym $] / /$ prek[tfrym]

Vep[+frym]

I prek/Vep
GENERAL 0

D4

M6

D6-7

D-I accused him, boy, girl, state etc. /Unë e akuzova atë, djalin, vajzën , shtetin etj.

M-You only accuse, but .... / Ju vetëm akuzoni, por ......

${ }^{1}$ Herbst, Heath, Roe, Gotz, A Valency Dictionary of English, Mouton de Gruyter, 2004.

21. Noun phrases [N] (new book, they, some of us, many children)

2. Adjectival phrases [ADJ] (fast to run)

3. Prepositional phrases [Prep N] (at home, around the neighborhood) 
D-They were accused by us. / Ata u akuzuan nga ne.

T-They were accused by you justly/unjustly intentionally/unintentionally. / Ata u akuzuan nga ju pa(me) të drejtë/pa (me) dashje.

Next we will try to give a model on how a verb head is reflected in a valency dictionary, for example in English, however, referring to the specific structures of Albanian.

The different meanings of the head are given in the beginning with Arab letters, for example, A - Accuse.

Firstly, we should clarify the fact that these patterns do not only foresee the structures where the verb is active, but also the passive ones and in certain cases when it is used as impersonal. Therefore, active and impersonal and passive definitions refer to these projections.

Moreover, we are trying to give all representative patterns, i.e. those that have the highest frequency of usage, at least at a neutral level (these are written in Roman letters).

If there is more than one complement in series, in a pattern, then they are marked with numbers, 1,2 etc.

Obligatory or optionally are elements to be foreseen in this inventory (obl, kont).

Semantic cases that we have combined with auxiliary elements of semantic components are simultaneously reflected in the pattern (Act - agent, affect - affected, Vepr-vepruesi, I prek-I prekuri etc.) Quantitative valency is given with a traditional terminology: transitive, 1, 2, 3 (e.g. $M D_{2}$, T etc.). The number shows the possible number of complements that could be found in that structure.

We have provided the phrases in Albanian, so we have noun phrases marked as [E].

All the foreseen structures in the inventory are given under the pattern with the indicators on the side for reference.

\section{Conclusion}

The above examples show that the verb and its structural and semantic distribution are clearly examined in the light of the Valency Theory. Thereupon, we suggest that the traditional voice/diathesis should be regarded as a valency process, because this way of reasoning could result in more accurate descriptions of the different levels of linguistic study with respect to the verb and the relations established by its distribution patterns. Also, the semantic valency of the verbs described in specific patterns becomes much clearer as compared to the traditional approach which almost ignores it.

\section{References}

Allerton. David J, Valency and the English Verb, London, Academic Press, 1982.

Dhrimo. A, Një vështrim mbi foljet me më se një reksion, SF, 1965, 2.

Dhimo. Th, Mbi klasifikimin e foljeve sipas valencës, Prishtinë, 2002.

Fillmore, Charles. Case for case, New Jork, 1968.

Fillmore, Charles. Case for case reopened, New Jork, 1977.

Fillmore. Charles, Valency Issues in FrameNet në Valency, Theoritical, Deskriptive and Cognitive Issues, 2005.

Fjalor i Gjuhës Shqipe, Akademia e Shkencave, Tiranë 1980.

Gramatika e gjuhës Shqipe , 2002, Tiranë, Akademia 
Herbst, Th., Heath, Roe, Gotz, A Valency Dictionary of English, Mouton de Gruyter, 2004.

Herbst. Thomas, English Valency Stuctures, Erlangen, EESE 2/99.

Herbst \&Schüller, Introduction to Syntactic Analysis, Tubingen, 2008.

Tesnière. L, Elements de Syntaxe Structurale, Paris, 1959.

Riza, S., Sistemi foljor i letrarishtes bashkohore, Tiranë ,1994/ A. Dhrimo

Xhaferri. G, Valenca e foljes në gjermanishte dhe në shqipe, Asdreni, Shkup, 2006. 